\title{
Obituary
}

doi:10.1038/sj.sc.3101303

\section{Dr Miguel Sarrias Domingo (1930-2002)}

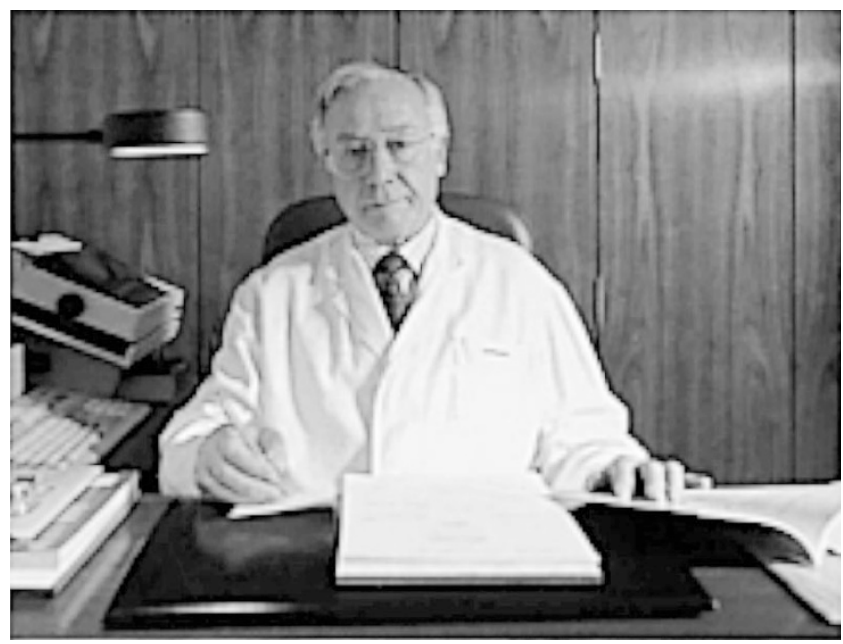

Miguel Sarrias was born in Barcelona on January 19th 1930 and he qualified in medicine and surgery at the University of Barcelona in 1955. Between 1958 and 1961 he studied under Dr Joseph Trueta, the Nuffield professor of orthopaedic surgery in Oxford, where he specialised in orthopaedic surgery and traumatology.

In 1962 he married Katherine Jane Brown, and they have two children, Marc and Sara.

In 1964 it was suggested to him by Señor Guillermo Gonzalez Gilbey that he should become the medical director of a hospital - the first of its kind in Spain dedicated to the treatment of people with paraplegic and tetraplegic injuries, and he then spent 7 months at Stoke Mandeville hospital in England studying under Dr Ludwig Guttmann where he learned the specialised treatment of people with spinal cord lesions. The new hospital was opened on November 27th 1965 and named after Sir Ludwig Guttmann, as the 'Instituto Guttmann, Centro de Lesionados Medulares'.

From then until his retirement in 1997 Dr Sarrias directed the work of the hospital, bringing it from obscure beginnings to national importance. His leadership was characterised by rigorous adherence to the best medical practice, a human understanding of his patients, and a constant capacity to explore new ways of treating patients, most notably, for example, in his promoting of the 'Barcelona technique' for the implantation of SARS (Sacral anterior roots electrostimulation). In addition, he developed a programme for the training of new specialists, and he enthusiastically supported the advancement of the subject and its academic societies both nationally and internationally.

He was the Spanish representative of IMSOP (The International Medical Society of Paraplegia), and he was both the initiator and president of SEP (Sociedad Española de Paraplejia). He was a member of the editorial board of the journal Paraplegia-Spinal Cord. In 1992 he organised the 'Annual Scientific Meeting' in Barcelona coinciding with the Paralympic Games; in the same year he was awarded the gold medal of the Club Européen de Santé and was elected a life member of the Academie Médicale Européene de Readaptation.

In retirement, his work for disabled people and for the Instituto Guttmann continued as a Patron of the Fundacion Instituto Guttmann and in his support for the construction of a new hospital at Badalona which is to be opened in the Spring of 2002 and will be one of the most advanced hospitals of its type in Europe.

Colleagues and friends of Dr Sarrias 